\title{
Возможные варианты правоотношений при привлечении частных инвестиций - концессия и государственно-частное партнерство
}

\author{
В. В. Холодкова ${ }^{1 凶}$ \\ ${ }^{1}$ Санкт-Петербургский государственный университет, Университетская набережная, д. 7/9, \\ 199034, Санкт-Петербург, Российская Федерация
}

Для цитирования: Холодкова В. В. Возможные варианты правоотношений при привлечении частных инвестиций - концессия и государственно-частное партнерство // Вестник Воронежского государственного университета. Серия: Экономика и управление. 2021. № 2. С. 40-48. DOI: https://doi.org/10.17308/ econ.2021.2/3383

\begin{abstract}
Предмет. Основным предметом исследований в работе являются правоотношения, возникающие при привлечении частных инвестиций в формате концессии и государственно-частного партнерства для реализации государственных проектов. Сегодня для решения многих задач, связанных с реализацией инфраструктурных проектов, государство активно привлекает частных инвесторов с использованием подобных схем финансирования. В российском законодательстве предусмотрено две основные формы: концессии и государственно-частного партнерства. Каждая форма имеет свои области применения, свои плюсы и минусы.

Цель. Сравнительный анализ вариантов совместной реализации проектов в формате государственно-частного партнерства и формате концессии.

Методология. В работе исследуются возможности реализации проекта в формате государственно-частного партнёрства, концессии, предлагаемые на законодательном уровне.

Результаты. По результатам сравнительного анализа указываются основные недостатки и достоинства каждого из подходов привлечения частного финансирования, также рассматривается практика подобных соглашений в России в настоящее время. Формируются рекомендации по реализации государственных проектов в тех или иных направлениях развития экономики. Анализ позволяет определить основные отрасли и сферы деятельности, для которых целесообразно реализовывать проекты привлечения частных инверторов с использованием формата концессии, а также сферы и отрасли реализации проектов в формате государственно-частного партнерства. Выводы. Важным аспектом анализа является оценка рисков как для государства, так и для частного инвестора, которые возникают в той или иной схеме привлечения частного инвестора к государственным проектам. Статья завершается выводами, которые содержат рекомендации по использованию различных форм привлечения частного инвестора для реализации государственных, инфраструктурных проектов в России в разных сферах экономики.
\end{abstract}

Ключевые слова: государственно-частное партнерство, концессия, правоотношения.

\section{Введение}

Любое предприятие для развития и расширения своей деятельности запускает и реализует определенный набор инвестиционных проектов. Большинство таких проектов требуют инвестиционных вложений, финансирования, осуществляемого в различной форме. В некоторых случаях предприятие имеет в своем распоряжении достаточно собственных средств (частных инвестиций) на реализацию проектов развития деятельности, иногда ему достаточно привлечь заемные средства, например в виде банковского финансирования, отдельные проекты реализуются с помощью бюджетных средств, возможно возникновение комбинированного варианта финансирования, но все большее развитие в современной экономике получает осуществление проектов в форме совместной реализации государства и частного инвестора, носящей название государственно-частного партнерства. Такой формат накладывает на частного инвестора

(C) Холодкова В. В., 2021

Вестник ВГУ. Серия: Экономика и управление. 2021. № 2. С. 40-48. 
Возможные варианты правоотношений при привлечении частных инвестиций...

ряд обязательств и ограничений, тем не менее при реализации масштабных проектов, а также проектов с участием государства эта форма финансирования является наиболее распространенной. Однако формы организации такого партнерства могут быть различны, в зависимости от принадлежности имущества, отрасли и прочих факторов.

Помимо того, что различают несколько видов государственно-частного партнерства, существует также ряд вариантов совместной реализации проектов для государства и частного партнера: концессии, лизинг, государственное финансирование.

Каждый из вариантов имеет свои законодательные особенности. В данной работе представлено сравнение наиболее известных и законодательно определенных (по российскому законодательству) форм реализации проектов, а именно в формате государственно-частного партнерства и формате концессии.

Реализация проектов в формате государственно-частного партнерства создает правовые условия для привлечения инвестиций в экономику Российской Федерации, а также способствует повышению качества работ, товаров и услуг, реализация которых осуществляется по согласованию с государственными органами, например, предоставление инфраструктуры, продажа воды, электроэнергии и др.

До сих пор существует определенная дискуссионность относительно выбора различных форм реализации совместных проектов государства и частных инвесторов в условиях российской действительности. Многие исследователи подчеркивают нечеткость разграничения этих форм, существующую в российском законодательстве, а также неопределенность некоторых механизмов их реализации.

В российском законодательстве данные формы развиваются, к сожалению, параллельно и не взаимосвязаны друг с другом. Так, например, Федеральный закон «О государственно-частном партнерстве» был принят только в 2015 г., тогда как Федеральный закон «О концессионных соглашениях» - в 2005 г. ${ }^{1}$ В то же время в разных регионах России существовали отдельные нормативно-правовые акты о порядке реализации проектов в формате государственно-частного партнерства ${ }^{2,3}$, например:

\footnotetext{
${ }^{1}$ Российская газета. 2005. Ст. 3830.

${ }^{2}$ Невское время. 19 апреля 2008. № 71.

${ }^{3}$ Вести. 20 октября 2011. № 98.
}

- Постановление Правительства Санкт-Петербурга от 16 апреля 2008 г. № 392 «О форме участия Санкт-Петербурга в государственно-частных партнерствах»;

- Закон Ленинградской области от 14 октября 2011 г. № 78-о3 «Об участии Ленинградской области в государственно-частных партнерствах».

В результате возникало большое число разночтений и неопределенных моментов, которые решались в основном в прецедентном порядке. Однако теперь можно констатировать, что с принятием 11 июля 2015 г. Федерального закона № 224-Ф3 «О государственно-частном партнерстве» муниципально-частном партнерстве в Российской Федерации и внесении изменения в отдельные законодательные акты (далее - Федеральный закон № 224-Ф3) многие спорные моменты ушли в прошлое ${ }^{4}$.

\section{Методы исследования}

Процедура конкурса в формате государственно-частного партнерства проходит в соответствии с Федеральным законом № 224-Ф3. Необходимо отметить, что до принятия данного закона реализация проектов на федеральном уровне на практике осуществлялась в основном в формате концессионных соглашений [5]. Однако в рамках регионов, при наличии соответствующих законов о государственно-частном партнерстве (в практике регионального законодательства субъектами РФ принято 56 региональных законов), реализация проектов осуществлялась в формате договоров государственно-частного партнерства, которые, однако, напоминали государственные контракты. Принятие федерального закона было необходимо для дальнейшего развития рынка инвестиционных проектов, реализуемых в формате государственно-частного партнерства, систематизации юридической базы российского законодательства и существующей региональной практики, а также для роста инвестиционной привлекательности таких проектов в России.

В рамках принятого закона по государственно-частному партнерству удалось достигнуть развития следующих направлений:

1) рост интереса финансирующих организаций к инвестиционным проектам, реализуемым на территории Российской Федерации;

${ }^{4}$ Российская газета. 2015. № 156. Ст. 6727. 
2) рост внутреннего рынка проектов государственно-частного партнерства;

3) определение основных понятий при реализации проектов государственно-частного партнерства в России;

4) формирование перечня основных возможных направлений, а также списка объектов, для которых возможно реализовывать проект в формате государственно-частного партнерства;

5) четкое выделение полномочий Российской Федерации, субъектов Российской Федерации и муниципальных образований (в сфере муниципально-частного партнерства);

6) инициатором проекта государственно-частного партнерства получил возможность стать публичный партнер.

Однако при подготовке указанного выше федерального закона не был решен ряд важных задач, связанных с созданием единой нормативной базы реализации проектов государственно-частного партнерства с учетом существующей западной практики реализации таких проектов, что могло бы способствовать их интеграции в сферу финансирования зарубежных инвесторов.

Теперь существует два законодательных акта, которые регулируют форму реализации проектов в формате государственно-частного партнерства, а также уточняют особенности заключения договоров в формате концессии. Хотя реализация проектов в данных форматах достаточно схожа, тем не менее можно выделить основные особенности реализации проектов по той или иной схеме 5 :

1) открытость и доступность информации по реализации проекта, который обеспечивается размещением информации на специально созданном сайте проекта, в печатных изданиях и других источниках. Это правило не касается проектов, которые затрагивают государственную тайну или иные сведения, охраняемые по закону;

2) в рамках реализации проектов в формате государственно-частного партнерства должна обеспечиваться конкуренция;

3) обеспечение равных прав сторон при реализации проекта;

4) соблюдение сторонами обязательств в соответствии с соглашением;

5) такие проекты должны отвечать требованиям справедливого распределения рисков и соответствующих им обязательств.

${ }^{5}$ Курс 2030: исследование развития инфраструктуры в России. URL: www.ey.com
В рамках Закона «О Концессионных соглашениях» реализация проекта заключается в принятия на себя концессионером обязательств по созданию (реконструкции) определенного объекта или имущества. Причем в данном случае право собственности на объект обязательно принадлежит концеденту. Такой объект или имущество будет являться объектом концессионного соглашения. Концессионер также может иметь право на эксплуатацию такого объекта. Срок эксплуатации оговаривается в концессионном соглашении.

При реализации таких проектов концессионное соглашение заключается на основе конкурсной процедуры. Процедура конкурса в формате концессии проводится в соответствии с Федеральным законом «О концессионных соглашениях».

Проведем сравнительный анализ вопросов заключения договора государственно-частного партнерства и концессионного соглашения по основным направлениям [9].

1. Процедура проведения конкурса

Рассмотрев вопросы механизмов проведения конкурсных процедур, можно заключить, что обе формы (и ГЧП, и концессия) предполагают два этапа проведения процедуры конкурса:

- предварительный отбор;

- конкурс.

2. Конкурсные требования

Для формирования технических и финансовых требований при проведении конкурса с целью заключения соглашения формируется конкурсная документация, содержащая в себе описание всех необходимых условий реализации проекта, состава имущества проекта, требований к составу исполнителей, а также иных условий, которые необходимо учитывать при реализации проекта.

3. Условия соглашения

В структуре концессионного соглашения указываются условия реализации проекта, а именно: за чей счет осуществляется строительство и реконструкция объектов, определенных соглашением, а также кто будет осуществлять их эксплуатацию и за чей счет. В конце срока действия соглашения (после возврата инвестиций) либо при его досрочном расторжении (с компенсацией) объект возвращается концеденту. Кроме того, в соглашении может быть предусмотрена возможность выхода инвестора из проекта.

Отметим, что принятыми федеральными законами предусмотрен ряд обеспечительных 
Возможные варианты правоотношений при привлечении частных инвестиций...

мер для инвесторов, таким образом можно утверждать, что гарантия возврата инвестиций как в форме ГЧП, так и в форме концессии высокая.

\section{4. Схема передачи имущества}

Предоставление земельных участков в разных формах осуществляется по-разному.

В форме ГЧП - земельные участки под существующими объектами передаются в аренду. Для новых участков необходимо соответствующим образом структурировать конкурсную процедуру.

Земельные участки, на которых осуществляется реализация проекта, как правило, находятся в собственности публичного инвестора, что не позволяет осуществлять его разделение.

В форме концессии обязательство по предоставлению земельных участков прямо предусмотрено законом о концессионных соглашениях. Земельные участки для реконструкции и строительства предоставляются без конкурса и определены в концессионном соглашении, что позволяет осуществить их постепенную передачу.

5. Собственность на объекты, созданные в ходе реализации проекта

Отметим, что тут возникает основное отличие форм реализации проекта. Так для форм ГЧП собственность на созданные объекты переходит к партнеру, который реализует проект.

В форме концессии по закону собственность на вновь созданные объекты сохраняется за концедентом (публичным партнером).

6. Риск потери (отчуждения) имущества инвестором в результате обращения взыскания на имущество либо банкротства

Риск потери имущества инвестором в результате обращения взыскания на имущество либо банкротства собственника имущества присутствует в форме ГЧП. Однако в форме Концессии такой риск отсутствует, так как имущественный комплекс - объект концессионного соглашения - по закону не может быть передан в залог.

7. Финансовая привлекательность

В обоих случаях реализация проекта осуществляется, как правило, только при наличии высокой привлекательности проекта для финансирующих организаций. Кроме того, как правило, финансовая модель проекта предусматривает возможность предоставления финансирующим организациям большого обеспечительного пакета (залог, передача прав и обязанностей по соглашению).
8. Тарифное регулирование

При наличии тарифного регулирования в отрасли реализации проекта необходимо учитывать имеющиеся ограничения.

При реализации формы ГЧП тарифы для тарифорегулируемых предприятий устанавливаются в соответствии с общим тарифным законодательством, при этом соглашением о ГЧП может быть предусмотрена гарантия получения дохода.

В концессионном соглашении иногда прописываются долгосрочные параметры регулирования, которые должны быть учтены при установлении тарифов, помимо этого возможно предусмотреть гарантию дохода концессионера.

9. Возможности использования различных инструментов привлечения финансирования

В форме ГЧП введены частичные ограничения на возможности использования различных инструментов финансирования. В рамках реализации ГЧП предусмотрены только такие формы финансирования:

- кредиты/займы (заемное финансирование);

- продажа акций при увеличении уставного капитала;

- бюджетные инвестиции (бюджетное финансирование).

Законодательство не предусматривает дополнительных механизмов по привлечению инвестиций на реализацию таких проектов.

В то же время в форме концессии привлечение финансирования по закону ничем не ограничено и включается в себя различные формы, к которым в том числе относятся: ние);

- кредиты/займы (заемное финансирова-

- продажа акций при увеличении уставного капитала;

- бюджетные инвестиции (бюджетное финансирование);

- инфраструктурные облигации (более простые условия включения в котировальный список).

Законодательством предусмотрены также возможности использования средств фондов инфраструктурных облигаций. Рентабельность проекта, реализуемого по такой схеме, закладывается на стадии формирования финансовой модели инвестиционного проекта при условии грамотного выбора платежного механизма. В проектах, реализуемых по схеме ГЧП, в финансовой модели в качестве доходной составляющей могут выступать платежи 
от потребителей, бюджетное финансирование, часто используются смешанные инструменты. При формировании финансовой модели проекта необходимо основываться на корректных прогнозах внешних финансовых величин, а также данных для оценки денежных потоков по проекту.

\section{Обсуждение результатов}

Проанализировав схемы, можно говорить, что механизм концессии позволяет в первую очередь распределить различного рода риски (финансовые, юридические, технические) между частным и публичным сектором [4]. Кроме того, при реализации проекта по схеме концессии возникает возможность закрепить обязательства сторон участников (концессионера и концедента), что позволяет достичь определенных концессионным соглашением целей и задач.

В рамках заключения концессионного соглашения концессионер также больше нацелен на достижение результата, в связи с тем что в концессионных проектах, как правило, предполагается акционерное финансирование, которым и рискует концессионер в случае невыполнения своих обязательств.

Реализация проекта в формате конкурсного отбора позволяет на конкурсной основе привлечь технологии и финансирование для реализации проекта. Механизм концессионного соглашения позволяет обеспечить больше гарантий возвратности средств для кредиторов в связи с наличием прямых соглашений, что позволяет концессионеру привлечь больший объем кредитов, что в свою очередь позволяет снизить максимальный рост тарифа (обеспечивает более плавный его рост при необходимости обеспечения большого объема инвестиций за счет тарифа) или сокращает максимальный годовой объем выплат из бюджета концессионеру (нагрузка на бюджет в рамках года будет меньше). Таким образом, передача частному сектору предприятия в формате концессии позволяет более эффективно осуществить оптимизацию расходов.

Еще одним достоинством формы концессии также будет являться большее число возможных участников процесса. Однако отметим, что к каждому конкретному проекту необходимо подходить индивидуально, поскольку для ряда объектов невозможно заключение концессионного соглашения, а иные объекты не могут быть задействованы в схеме ГЧП.

В частности, к объектам, в отношении которых может быть заключено только концес- сионное соглашение, относятся государственные автомобильные дороги, метро, некоторые объекты жилищно-коммунального хозяйства и даже объекты водоснабжения и водоотведения (проект «Чистая вода»).

Что касается существующей практики заключения договоров ГЧП и концессии в Санкт-Петербурге, то большая часть договоров пока заключается в формате концессии. К таким договорам можно отнести строительство Западного скоростного диаметра, проект строительства и реконструкции аэропорта Пулково, строительство скоростной платной автодороги «Москва - Санкт Петербург». Проекты в формате концессии удобно заключать для объектов жилищно-коммунальной сферы.

В Ленинградской области также много подобных соглашений, например, соглашение с AO «Газпромтеплоэнерго», которое осуществляет реконструкцию и строительство котельных и сетей, в размере около 20 млрд руб. Окупаемость проекта формируется в рамках тарифов на тепло.

Отметим, что основным недостатком такой формы реализации инфраструктурных проектов является то, что установленные тарифы могут не покрывать затраты на производство, а повышение их до уровня рентабельности создает дополнительное социальное напряжение или невозможно.

\section{Олимпийские концессии}

Основная сфера применения механизмов ГЧП в спортивной индустрии - строительство спортивных объектов (сооружений). Из механизмов, прямо предусмотренных законодательством, для создания спортивной инфраструктуры наиболее применимы концессионные соглашения. Закон о концессионных соглашениях определяет возможность создания и реконструкции спортивных объектов в рамках концессионной формы.

В России механизмы ГЧП широкого применения в строительстве спортивных объектов пока не получили. Бюджетная стройка спортивных объектов в рамках спортивных мероприятий международного уровня - зимней Олимпиады 2014 г. и Универсиады 2014 г. - подтверждение этому. Одной из причин такого игнорирования ГЧП как механизма создания спортивной инфраструктуры могут быть сжатые сроки строительства, не позволившие структурировать потенциальные проекты ГЧП и провести конкурсные процедуры. Возможно, высокая важность меропри- 
ятий не позволила их организаторам использовать такие проекты в качестве испытательных площадок для применения ГЧП в новых для России сферах.

\section{Заключение}

Преимущества реализации проектов в формате ГЧП или концессии очевидны. Это возможность привлечения инвестиций в развитие инфраструктуры региона там, где бюджетных источников недостаточно [1].

Принятие общих правил игры в законодательстве в этой сфере существенным образом снижает риски реализации региональных проектов ГЧП и концессии, такие как риски правовой переквалификации отношений сторон в иные юридические конструкции, а также риски нарушения законодательства о приватизации, о государственных закупках и пр.

Тем не менее Федеральный закон «О концессионных соглашениях» так и остался обособленным законом, хотя нормы, регулирующие эти два направления, должны быть типичны, поскольку концессионное соглашение является формой ГЧП. Однако можно смело заключить, что принятие нового закона не реши-

\section{Библиографический список}

1. Вандышева О. П., Федюшина Е. А. Инвестиции в человеческий капитал как движущая сила развитии инновационной экономики // Современная экономика: проблемы и решения. 2018. № 1 (97). C. 55-62.

2. Лихачев B., Азанов М. Практический анализ современных механизмов государственно-частного партнерства в зарубежных странах, или Как реализовать ГЧП в России : в 3 ч. // Финансы. Экономика. Безопасность. 2004. № 5. С. 2-10.

3. Лихачев В., Азанов М. Практический анализ современных механизмов государственно-частного партнерства в зарубежных странах, или Как реализовать ГЧП в России : в 3 ч. // Финансы. Экономика. Безопасность. 2005. № 1. С. 2-8.

4. Лихачев B., Азанов М. Практический анализ современных механизмов государственно-частного партнерства в зарубежных странах, или Как реализовать ГЧП в России : в 3 ч. // Финансы. Экономика. Безопасность. 2005. № 2. С. 4-8.

5. Попов В. Г., Романова Н. Ю., Свешникова Е. В. Инвестиционная активность как фактор повышения конкурентоспособности региона // Современная экономика: проблемы и решения. 2020. № 6 (126). С. 149-158.

6. Полянин А. В., Головина Т. А., Авдеева И. Л. Менеджмент в системе государственно-частного ло проблему систематизации понятий (не появилось подробного описания форм ГЧП, не возникло единого понятия ГЧП, нет четкого структурирования проектов), а отсутствие базовых понятий приводит к проблемам в привлечении финансирования в подобные проекты, так как банкам сложно оценить риски проектов, а также соответствие того или иного проекта заявленной форме.

В новом законодательстве установлен закрытый перечень возможных способов участия сторон в соглашении о ГЧП, указан подробный перечень объектов соглашений. Тем не менее ряд вопросов остается до конца нерешенным [2], наиболее важными с точки зрения защиты прав и интересов инвесторов являются вопросы обеспечения прав и предоставления земельных участков, которые подробно не прописаны в законодательстве. Таким образом, развитие законодательной базы в этой сфере должно продолжаться.

\section{Конфликт интересов}

Автор декларирует отсутствие явных и потенциальных конфликтов интересов, связанных с публикацией настоящей статьи.

партнерства : механизм «инфраструктурной ипотеки» // Вестник Воронежского государственного университета. Серия: Экономика и управление. 2018. № 1. С. 161-168.

7. Рисин И. Е., Козуб Л. А. Ключевые направления повышения инвестиционной активности высшей школы региона // Вестник Воронежского государственного университета. Серия: Экономика и управление. 2018. № 4. С. 125-130.

8. Холодкова В. В. Перспективы реализации государственно-частного партнёрства в России // Менеджмент в России и за рубежом. 2010. № 6. С. 27-34.

9. Холодкова В. В. Проблемы реализации проектов государственно-частного партнёрства в России // Менеджмент в России и за рубежом. 2015. № 6. С. 19-24.

10. Холодкова В. В. Оценка эффективности деятельности предприятия с использованием моделей параметрического линейного программирования // Вестник Воронежского государственного университета. Серия: Экономика и управление. 2016. № 1. С. 153-157.

11. Ibyatov F. M., Zotov V. B., Cherkasova M. A. Digital Transformation of the Market for Investment Projects with State Participation // Studies in Systems, Decision and Control. 2021. Vol. 314. P. 847851 . 
12. Lima S., Brochado A., Marques R. C. Publicprivate partnerships in the water sector: A review // Utilities Policy. 2021. Vol. 69. 101182.

13. Schmitz P. W. Optimal ownership of public goods under asymmetric information // Journal of Public Economics. 2021. Vol. 198. 104424

14. Silaghi F., Sarkar S. Agency problems in publicprivate partnerships investment projects // European
Journal of Operational Research. 2021. Vol. 290 (3). P. 1174-1191.

15. Vaslavskaya I. Y., Vaslavskiy Y. I. Public-Private Partnership and Resolving the Societal Crisis Caused by the COVID-19 Pandemic // IOP Conference Series: Earth and Environmental Science. 2021. Vol. 666 (3). 062108.
Холодкова Виктория Владимировна, кандидат экономических наук, доцент экономического факультета, доцент кафедры экономической кибернетики, Санкт-Петербургский государственный университет, Санкт-Петербург, Российская Федерация

E-mail: holodkova_v@mail.ru

ORCID ID: 0000-0002-1523-8412
Поступила в редакцию 03.12.2020

Подписана в печать 15.03.2021 


\section{Possible alternatives for legal relations in the process of attracting private investment: concessions and public-private partnerships}

\section{V. Holodkova ${ }^{\circledR}$}

${ }^{1}$ Saint-Petersburg State University, 7/9 Universitetskaya Emb., 199034 Saint Petersburg, Russian Federation

Cite as: Holodkova, V. V. (2021). Possible alternatives for legal relations in the process of attracting private investment: concessions and public-private partnerships. Proceedings of Voronezh State University. Series: Economics and Management. 2, 40-48. (In Russ., abstract in Eng.). DOI: https://doi.org/10.17308/econ.2021.2/3383

Subject. The main subject of the investigation presented in the article is legal relations arising in the process of attracting private investments involving concessions or public-private partnerships for the benefit of the implementation of governmental projects. Today, to solve numerous tasks associated with the implementation of infrastructure projects, the government is actively attracting private investors, which involves using similar financing mechanisms. Russian legislation provides for two basic forms: concessions and public-private partnerships. Each format has its own areas of application, its advantages and disadvantages.

Objectives. A comparative analysis of options for joint implementation of projects involving public-private partnerships and concessions.

Methods. The analysis considered the opportunities provided by the legislation to implement specific mechanisms involving public-private partnerships or concessions. In addition, the study involved a comparative analysis of each form of tender procedure, tender requirements, terms and conditions of the agreement, the possibilities for tariff regulations and the attraction of loaned funds, and other aspects.

Results. According to the results of the comparative analysis, the main advantages and disadvantages of each approach to attracting private financing were identified. The study also provides the analysis of case studies for similar agreements currently implemented in Russia. Following the results, recommendations were made for the implementation of governmental projects in different areas of the economy. The analysis allowed identifying the main sectors and areas of activity for which it is advisable to use the format of concessions to implement a project involving the attraction of private investors and the sectors and areas in which the format of a public-private partnership is preferable.

Conclusions. An important aspect of the analysis is the assessment of involved risks for the state and private investors, which arise in case of using each mechanism of attracting private investments for governmental projects. The article concludes with recommendations regarding the use of each format of attracting private investors to implement governmental infrastructure projects in Russia in different spheres of the economy.

Key words: public-private partnership, concession, legal relations.

\section{Conflict of Interest}

The authors declare the absence of obvious and potential conflicts of interest related to the publication of this article.

\section{References}

1. Vandysheva, O. P. \& Fedyushina, E. A. (2018) Investment in human capital as the driving furce of innovation economy development. Modern economics: problems and solutions. 1(97), 55-62.(In Russian).
2. Likhachev, V. \& Azanov, M. (2004) Practical analysis of modern mechanisms of public-private partnership in foreign countries, or How to implement PPP in Russia. In 3 parts. Finance. Economy. Security. 5, 2-10. (In Russian). 
3. Likhachev, V. \& Azanov, M. (2005) Practical analysis of modern mechanisms of public-private partnership in foreign countries, or How to implement PPP in Russia. In 3 parts. Finance. Economy. Security. 1, 2-8. (In Russian).

4. Likhachev, V. \& Azanov, M. (2005) Practical analysis of modern mechanisms of public-private partnership in foreign countries, or How to implement PPP in Russia. In 3 parts. Finance. Economy. Security. 2, 4-8. (In Russian).

5. Popov, V. G., Romanova, N. Y. \& Sveshnikova, E. V. (2020) Investment activity as a factor of increasing regional competitiveness. Modern economics: problems and solutions. 6(126), 149-158. (In Russian).

6. Polyanin, A. V., Golovina, T. A. \& Avdeeva, L. I. (2018) Management in the public-private partnership: the mechanism of "infrastructure mortgage". Proceedings of Voronezh State University. Series: Economics and Management. 1, 161-168. (In Russian).

7. Risin, I. E. \& Kozub, L. A. (2018) Key areas of improvement investment activity higher school of the region. Proceedings of Voronezh State University. Series: Economics and Management. 4, 125-130. (In Russian).

8. Holodkova, V. V. (2010) Prospects for the implementation of public-private partnership in Russia. Management in Russia and abroad. 6, 27-34. (In Russian).
9. Holodkova, V.V.(2015) Problems of implementation of public-private partnership projects in Russia. Management in Russia and abroad. 6, 19-24.(In Russian).

10. Holodkova, V. V. (2016) Assessment of efficiency of activity of the enterprise with use of models of parametrical linear programming. Proceedings of Voronezh State University. Series: Economics and Management. 1, 153 - 157. (In Russian).

11. Ibyatov, F. M., Zotov, V. B. \& Cherkasova, M. A. (2021) Digital Transformation of the Market for Investment Projects with State Participation. Studies in Systems, Decision and Control. 314, 847-851.

12. Lima, S., Brochado, A. \& Marques, R. C. (2021) Public-private partnerships in the water sector: A review. Utilities Policy. 69, 101182.

13. Schmitz, P. W. (2021) Optimal ownership of public goods under asymmetric information. Journal of Public Economics. 198, 104424.

14. Silaghi, F. \& Sarkar, S. (2021) Agency problems in public-private partnerships investment projects. European Journal of Operational Research. 290(3), 11741191.

15. Vaslavskaya, I. Y. \& Vaslavskiy, Y. I. (2021) Public-Private Partnership and Resolving the Societal Crisis Caused by the COVID-19 Pandemic. IOP Conference Series: Earth and Environmental Science. 666(3), 062108.
Victoria V. Holodkova, Cand. Sci. (Econ.), Assoc. Prof., Economics Faculty, Saint-Petersburg State University, Saint Petersburg, Russian Federation

E-mail: Holodkova_v@mail.ru

ORCID ID: 0000-0002-1523-8412
Received 03.12.2020

Accepted 15.03.2021 